\title{
Effects of Insulin Resistance Induced by Dexamethasone on Bone Mass in Ovariectomized Rats
}

\author{
Mahmoud H. El-Bidawy ${ }^{1,2}$ \\ ${ }^{1}$ Department of BMS, Division of Physiology, College of Medicine, Prince Sattam Ibn Abdulaziz University, AlKharj, Saudi Arabia \\ ${ }^{2}$ Department of Medical Physiology, Faculty of Medicine, Cairo University, Cairo, Egypt
}

Email address:

melbidawy2005@hotmail.com.

\section{To cite this article:}

Mahmoud H. El-Bidawy. Effects of Insulin Resistance Induced by Dexamethasone on Bone Mass in Ovariectomized Rats. International Journal of Diabetes and Endocrinology. Vol. 3, No. 3, 2018, pp. 41-49. doi: 10.11648/j.ijde.20180303.12

Received: September 17, 2018; Accepted: October 11, 2018; Published: November 7, 2018

\begin{abstract}
Glucocorticoids therapy is the most common cause of secondary iatrogenic osteoporosis. The bone loss occurs predominantly due to a decrease in bone formation, although increased bone resorption also occurs. Insulin resistance is the key pathology in type 2 diabetes negatively influence bone remodeling and leads to reduced bone strength. Loss of sex steroids, particularly oestradiol, as in ovariectomized rats,leads to increased skeletal remodeling over and above the age-related increment, together with excessive osteoclast activity. In this study, ovariectomy DEX group has highly significant increase in relative cortical resorptioncompared to ovaiectomy and sham DEX groups, also ovariectomy and DEX group has highly significant decrease in bone thickness compared to ovariectomy and sham DEX groups. The consequent increase in remodeling activation increases the overall resorption rate without a compensatory increase in formation, leading to rapid bone loss. This negative effect on bone which is due to the glucocorticoid excess is also mediated by indirect mechanisms such as the calcium malabsorption and hypercalciuria. In response to the enhanced supply of calcium from the skeleton, PTH secretion tends to be diminished, thereby reducing vitamin $\mathrm{D}[1,25(\mathrm{OH}) 2$ cholecalciferol] concentration with a consequent reduction in calcium absorption.
\end{abstract}

Keywords: Dexamethasone, Insulin Resistance, Ovariectomy, Bone Mass, Osteoporosis

\section{Background}

An excess of cortisol, as seen in Cushing's syndrome or with clinical administration of glucocorticoids that is used to treat acute and chronic inflammatory diseases, leads to symptoms of abdominal obesity, hypertension, glucose intolerance or diabetes and dyslipidemia, all of which are also features of insulin resistance [1-2].

Insulin resistance increases the risk of developing type 2 diabetes.The pathophysiology of type 2 diabetes mellitus (T2DM) may negatively influence bone formation [3-6].

Glucocorticoids modify osteoblastic cells through inhibiting osteoblast maturation and reduce their synthetic capacity, thereby reducing the amount of bone formed during each remodeling cycle [7]

Osteoporosis is a skeletal disease characterized by low bone mass and the structural deterioration of bone resulting in, increase susceptibility to fractures [8] .Imbalance between bone formation and bone resorption is the predominant mechanism behind osteoporosis [9].

\section{Objectives}

In this study we injected dexamethasone in rats to induce insulin resistance and investigated the insulin resistance effects on bone mass either alone or in addition to ovariectomy in ovariectomized rat models.

\section{Materials and Methods}

\subsection{Animals}

24 Wistar female rats 8-10 WEEKS (155 -170 g) were obtained from animal house of institute of ophthalmology, Giza, Egypt. Rats were housed individually, allowed to acclimatize the new environment, free access to water and food ad libitum, temperature $(23 \mathrm{C})$ and exposure to 12 hours 
day/night cycle.

Rats underwent overictomy surgery as follow:

Anaesthesia: Ketamine $40 \mathrm{mg} / \mathrm{kg}$ mixed with xylazine 20 $\mathrm{mg} / \mathrm{kg}$ and injected intra peritoneal. The abdominal hair was shaved abdominal wall was sterilized and midline anterior abdominal was incised. Both ovaries were removed. The postoperative antibiotic was cephalosporine $20 \mathrm{mg} / \mathrm{kg}$ intramuscular, once/day for 3 days. The post operative analgesia was $\mathrm{Na}$ Diclofenac $2 \mathrm{ml} /$ rat twice/day for 3 days. The rats were allowed to 2 weeks recovery before any additional procedures. 14days, and were allowed to rest for 12 hours before the surgery.

At end of experiment, blood samples were taken through puncture of the aorta. Bones of tibia are immediately removed for biochemical and histological studies.

\subsection{Drugs and Chemicals}

Dexamethasone [DEX] sodium phosphate powder and cholesterol powder were obtained from Sigma-Aldrich Company, USA. Commercial cinnamon powder was prepared as a water extract at a concentration of $60 \mathrm{~g} / 100 \mathrm{ml}$ distilled $\mathrm{H} 2 \mathrm{O} 2$

Biochemical studies:

1-Serum glucose and insulin.

2-Biochemical markers of bone metabolism [serum alkaline phosphatase (ALP) activity, $\mathrm{P}$ and Ca] 3Histological study of tibia bone (H \& E)

\subsection{Histopathological Examinations}

Specimens taken and sectioning

The animals were sacrificed by using chloroform inhalation and the femurs were carefully dissected and cleared from adjacent muscles, then immediately fixed in neutral buffered formaldehyde for 2 days. After fixation, the femurs were processed for preparation of decalcified specimens. Decalcification was performed byusing the chelating agent ethylene diamine tetra acetic acid in the form of its disodium salt $(5.5 \mathrm{~g}$ ethylene diamine tetra acetic acid in $90 \mathrm{ml}$ distilled water and $10 \mathrm{ml}$ formaldehyde $37-40 \%$ ). Decalcification was carried out for 4 weeks, during which time the decalcifying solution was changed every day. The decalcified specimens were dehydrated and processed to form paraffin blocks. Serial longitudinal sections, parallel to the long axis of the bones extending from one-third to one-half the thickness of the distal femur, were prepared. Then sections of $5 \mu \mathrm{m}$ thickness were subjected to:

\subsection{Bone Histomorphometric Studies}

1-Outer cortical bone thickness: mean width of outer cortical bone. This was measured by drawing a perpendicular line from the periosteum to the endosteum [10]

2- Relative bone resorption eroded surface (\%): percentage of compact bone surface with characteristic features of resorption, including surfaces with and without osteoclasts [11].

$$
\frac{\text { Length of eroded trabecular surface } \%}{\text { Total length of trabecular surface }}
$$

The cortical thickness was determined at five levels ( $0.5 \mathrm{~mm}$ apart), starting $0.2 \mathrm{~mm}$ below the lowest point of the growth plate. All bone histomorphometric measurements were taken, beginning at more than $1.2 \mathrm{~mm}$ from the growth plate-metaphyseal junction to exclude the primary spongiosa [12].

\subsection{Statistical Analysis}

Data are expressed as mean \pm S.E.M. Statistical evaluation was performed by one-way analysis of variance [ANOVA] followed by Turkey test for multiple comparisons. All analyses were performed with SPSS software package [version 18]. $\mathrm{P}<0.05$ was selected as the criterion for statistical significance.

\section{Results}

Dexamethasone injection in sham operated group induced significant increase in blood glucose and insulin levels compared to sham control group. Also Dexamethasone injection in ovariectomized rats results in highly significant increase in glucose and insulin levels compared to sham control ,sham DEX and ovariectomized groups

Ovariectomized groups showed significant increase in blood glucose and highly significant increase in insulin levels compared to sham control group and sham DEX groups

Ovariectomy + DEX group showed very highly significant increase in glucose and insulin compared to sham sham control, Sham + DEX and ovariectomized groups

Table 1. (Figures 1 \& 2) Effects of Dexamethasone treatment and ovariectomy on glucose and, insulin levels.

\begin{tabular}{|c|c|c|c|c|c|c|c|}
\hline \multirow[b]{2}{*}{ Glucose $\mathrm{mmol} / \mathrm{l}$} & \multirow{2}{*}{$\begin{array}{l}\text { Sham control } \\
6.61+0.87\end{array}$} & \multicolumn{2}{|c|}{ Sham DEX } & \multicolumn{2}{|c|}{ Ovariectomy } & \multicolumn{2}{|c|}{ Ovariectomy + DEX } \\
\hline & & 10.72 & $+1.44^{*}$ & 8.80 & $+0.33 *$ & $13.77+1.8$ & $16 * \$ \#$ \\
\hline Insulin uIU/ml & $7.188+0.70$ & 10.15 & $+0.54 *$ & 8.62 & $+0.569 * \#$ & $16.68+0.79$ & $9 * \# \$$ \\
\hline
\end{tabular}

*: statistically significant compared to corresponding value in sham control group $(\mathrm{P}<0.05)$

\#: statistically significant compared to corresponding value in sham DEX group $(\mathrm{P}<0.05)$

$\$$ : statistically significant compared to corresponding value in ovariectomy group $(\mathrm{P}<0.05)$ 


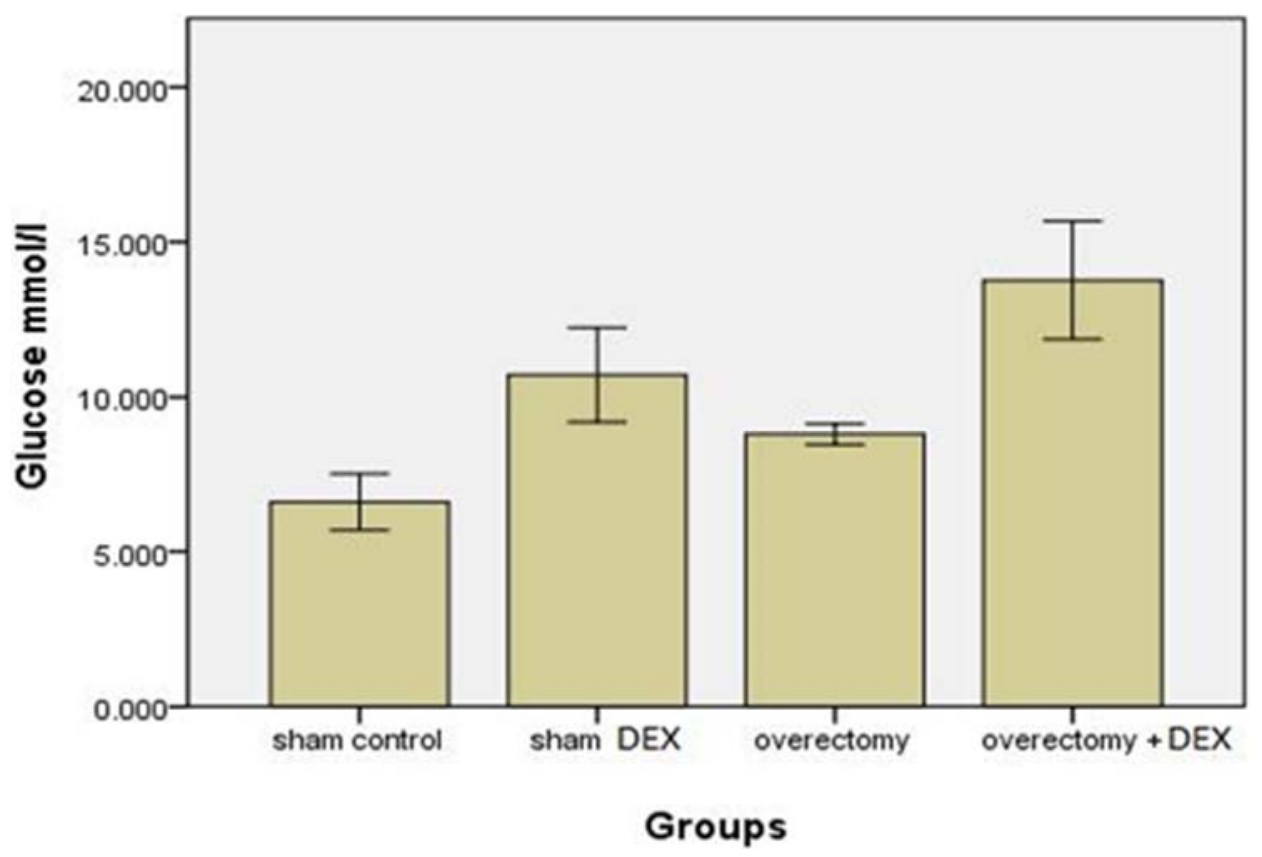

Figure 1. Effects of Dexamethasone treatment and ovariectomy on glucose level.

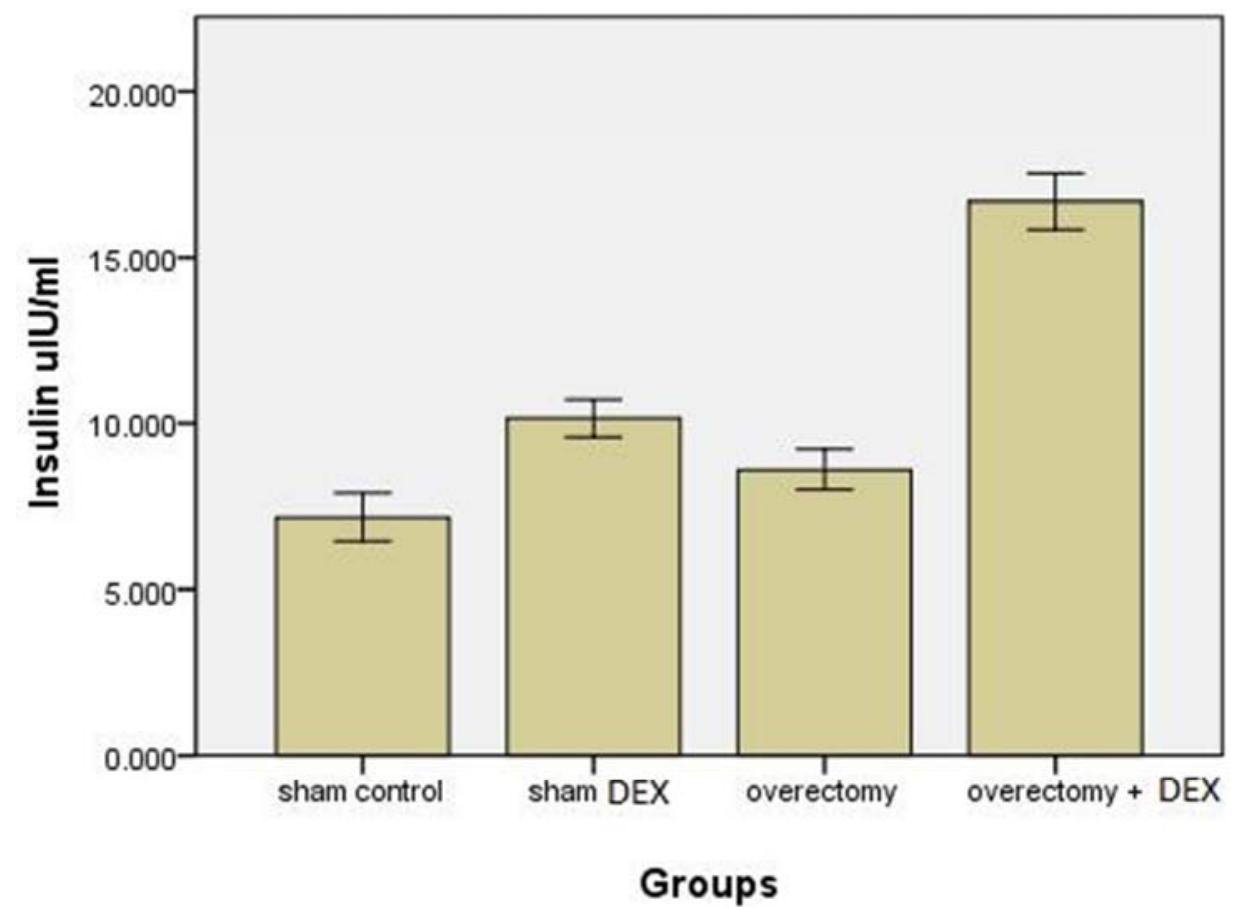

Figure 2. Effects of Dexamethasone treatment and ovariectomy on insulin level.

Table 2. (Figures 3 \& 4): Effects of Dexamethasone treatment and ovariectomy on calcium, phosphorus and alkalinephosphatase levels.

\begin{tabular}{lllll}
\hline & Sham control & Sham DEX & Ovariectomy & Ovariectomy + DEX \\
\hline Calcium $\mathrm{mg} / \mathrm{dl}$ & $10.52+1.196$ & $10.12+0.634$ & $13.62+2.46042$ & $15.52+3.84^{*}$ \\
Phosphorus mg/dl & $4.28+0.46$ & $4.05+0.45$ & $4.90+0.33$ & $5.10+0.77 \#$ \\
$\mathrm{ALP} \mathrm{u} / \mathrm{ml}$ & $123.83+2.91$ & $153.85+31.18$ & $207.83+9.04 * \#$ & $217.87+6.75 * \#$ \\
\hline
\end{tabular}

*: statistically significant compared to corresponding value in sham control group $(\mathrm{P}<0.05)$

\#: statistically significant compared to corresponding value in sham DEX group $(\mathrm{P}<0.05)$

$\$$ : statistically significant compared to corresponding value in ovariectomy group $(\mathrm{P}<0.05)$

Dexamethasone injection in sham operated group has insignificant increase in both calcium and phosphorous level and also insignificant increase in alkaline phosphatase enzyme compared to sham control. 
Ovariectomy has insignificant increase in both calcium and phosphorous level and very highly significant increase in alkaline phosphatase enzyme compared to sham control and sham DEX groups.

Ovariectomy + Dex has significant increase in both calcium and phosphorous levels and very highly significant increase in alkaline phosphatase enzyme compared to sham DEX groups and significant increase compared to ovariectomized group.

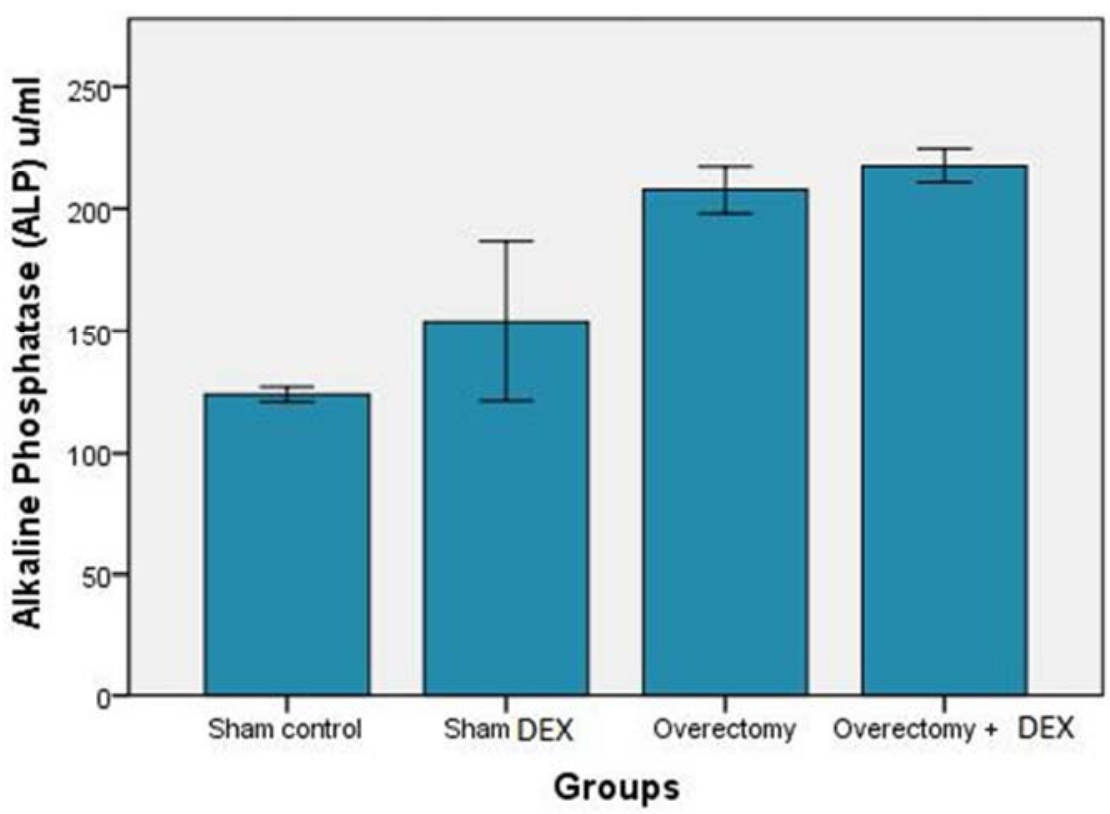

Figure 3. Effects of Dexamethasone treatment and ovariectomy on alkaline phosphatase levels.

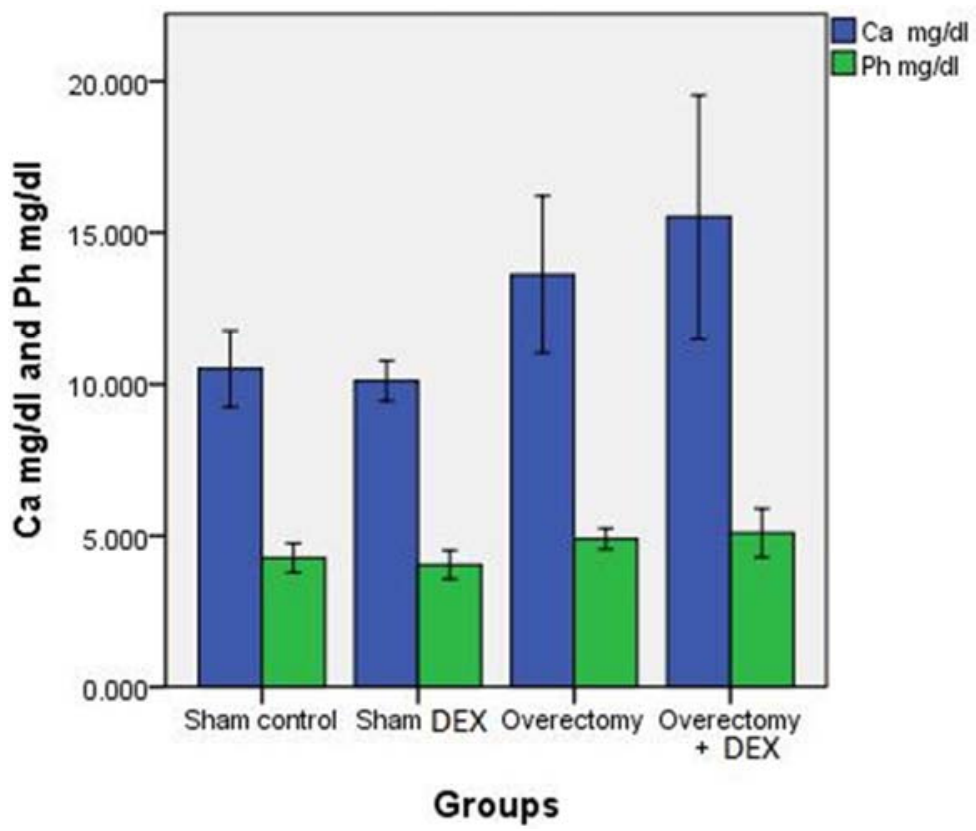

Figure 4. Effects of Dexamethasone treatment and ovariectomy on calcium and phosphorus.

Histopathological results:

Table 3. (Figures 5 \& 6): Effects of Dexamethasone treatment and ovariectomy on Bone thickness and cortical resporption.

\begin{tabular}{llll}
\hline & Sham control & Sham DEX & Ovariectomy \\
\hline Bone trabeculae thickness $\mu \mathrm{m}$ & $93.33+3.266$ & $86.33+.428$ & $86.33+4.082$ \\
Relative cortical resorption $\%$ & $12+0.63$ & $12.83+0.98$ & $28+0.89 * \# \$$ \\
\hline
\end{tabular}

*: statistically significant compared to corresponding value in sham control group $(\mathrm{P}<0.05)$

\#: statistically significant compared to corresponding value in sham DEX group $(\mathrm{P}<0.05)$

$\$$ : statistically significant compared to corresponding value in ovariectomy group $(\mathrm{P}<0.05)$ 
Sham DEX group has insignificant decrease in bone trabeculae thickness compared to sham control group.

Ovariectomy group has insignificant decrease in bone trabeculae thickness compared to Sham DEX and Sham control.

Ovariectomy and DEX group has highly significant decrease in bone thickness compared to ovariectomy and sham DEX groups.

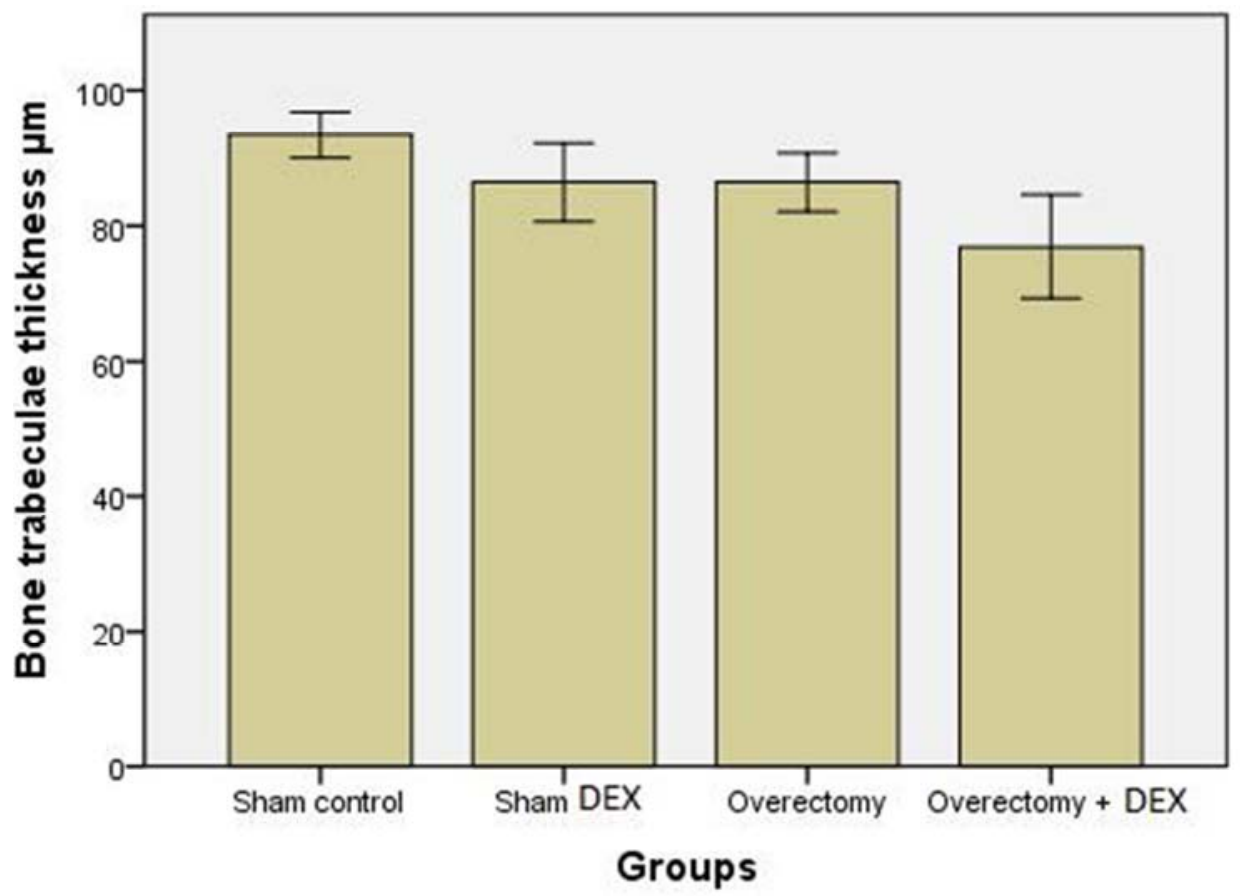

Figure 5. Effects of Dexamethasone treatment and ovariectomy on Bone trabeculae thickness.

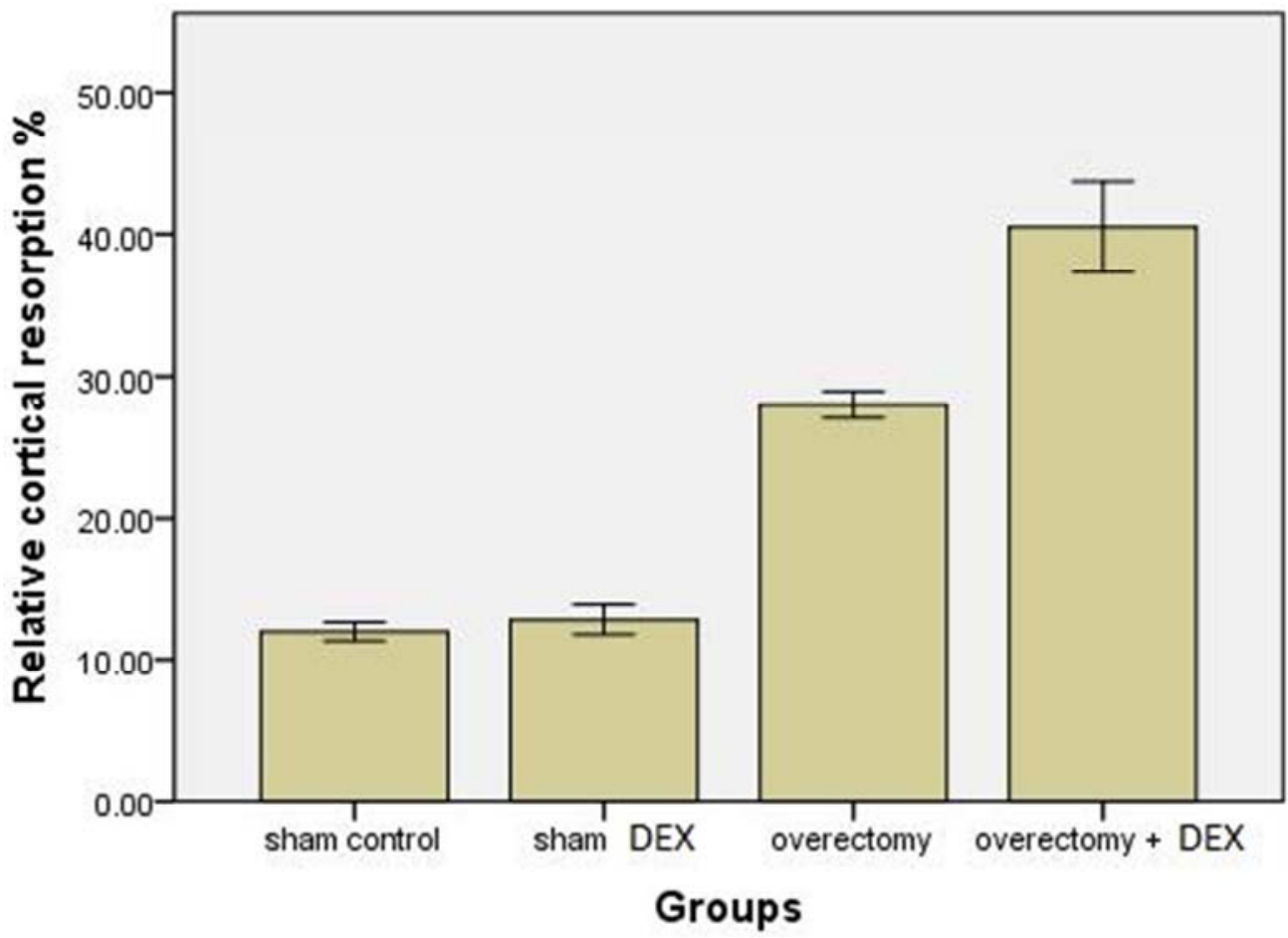

Figure 6. Effects of Dexamethasone treatment and ovariectomy on Bone relative cortical resporption \%.

Sham DEX group has insignificant increase in relative cortical resporption \% compared to sham control group Ovariectomy group has significant increase in relative cortical resorption \% compared to sham DEX group.
Ovariectomy DEX group has highly significant increase in relative cortical resorption compared to ovaiectomy and sham DEX groups. 


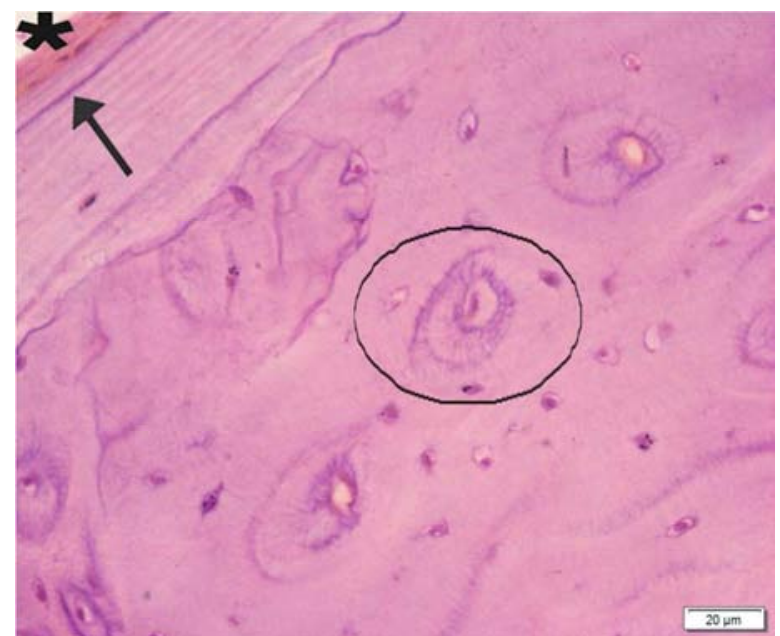

Figure 7. A photomicrograph of a longitudinal section of rat femur compact bone from Sham group showing Haversian system and osteocytes inside their lacunae (circle). Regular periosteum (Star) with subperiosteal bone deposition appearing as distinct basophilic cement line (arrow). (H\&E $\times 400)$.

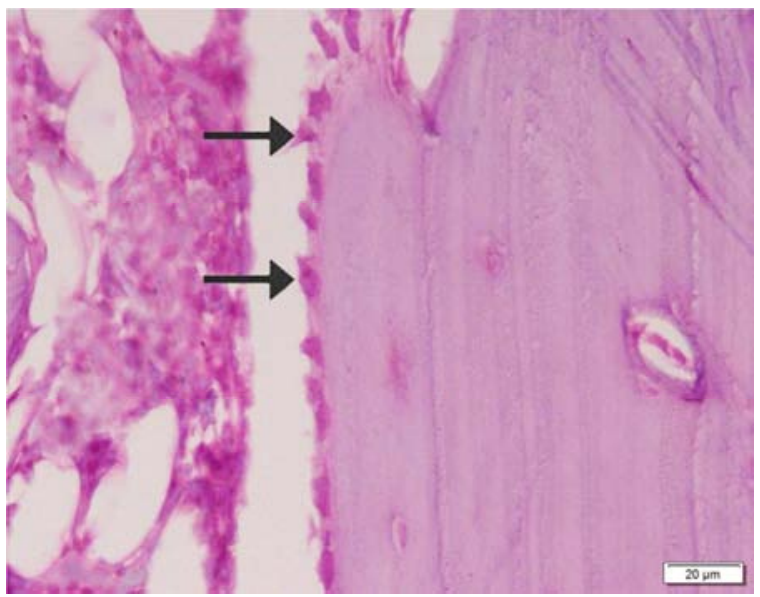

Figure 8. A photomicrograph of a longitudinal section of rat femur compact bone from Sham control group showing smooth endosteal surface that is lined with active osteoblasts (arrows). The bone marrow cavity consists of bone marrow cells and few adipocytes. $(H \& E \times 400)$.

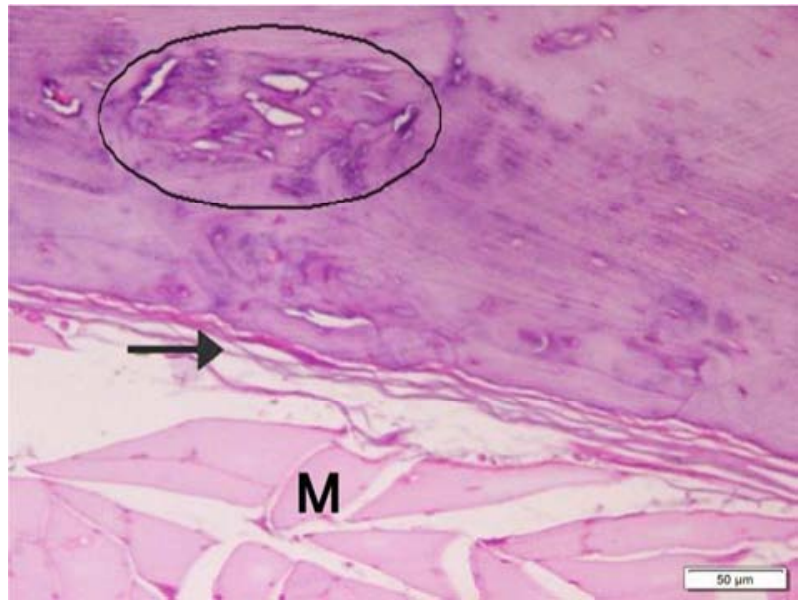

Figure 9. A photomicrograph of a longitudinal section of rat femur compact bone from group II (Sham DEX) showing irregular periosteum (arrow). Local resorption areas (circle) are seen. Note the skeletal muscle (M). (H\&E $\times 200)$.

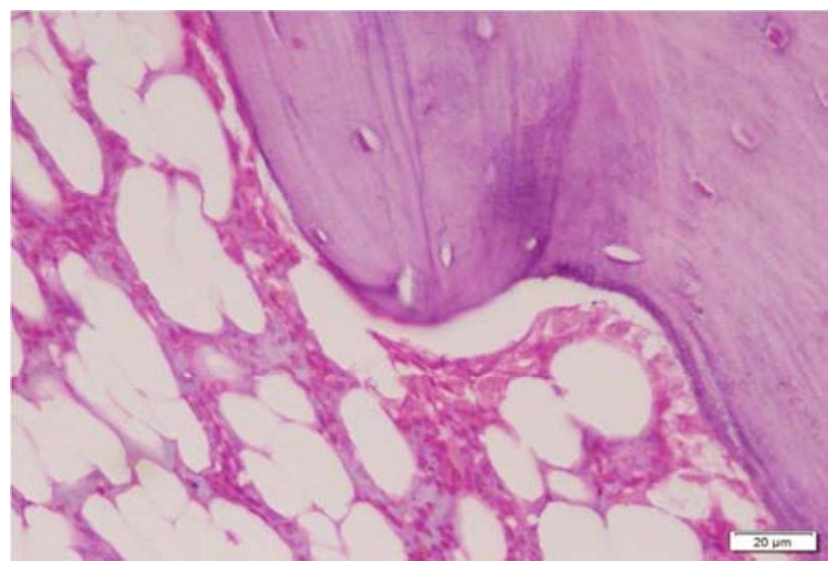

Figure 10. A photomicrograph of a longitudinal section of rat femur compact bone from group II (sham DEX) showing irregular endosteum . Many adipocytes are seen in the bone marrow cavity. $(H \& E \times 400)$.

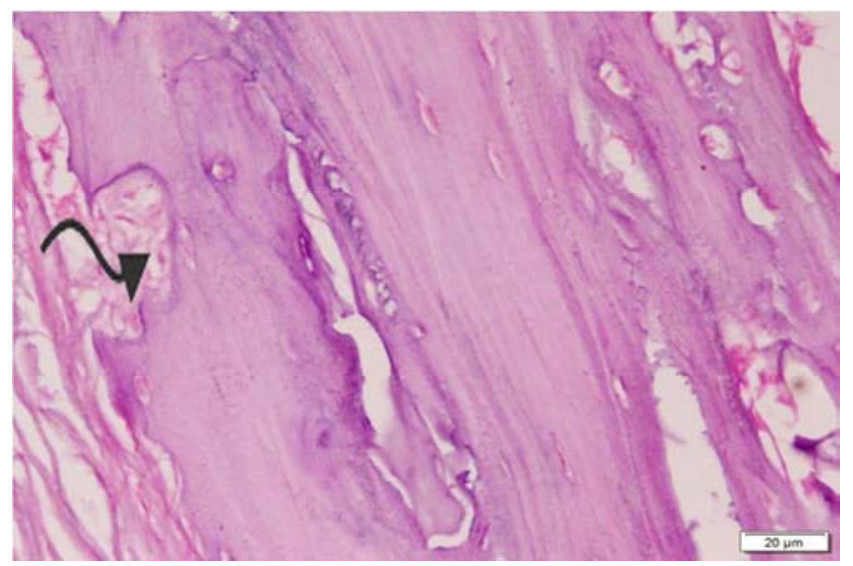

Figure 11. A photomicrograph of a longitudinal section of rat femur compact bone from group III (OVARIECTOMY) showing irregular periosteum (curved arrow) with no signs of subperiosteal new bone deposition. Notice the resorption cavities. $(H \& E \times 400)$.

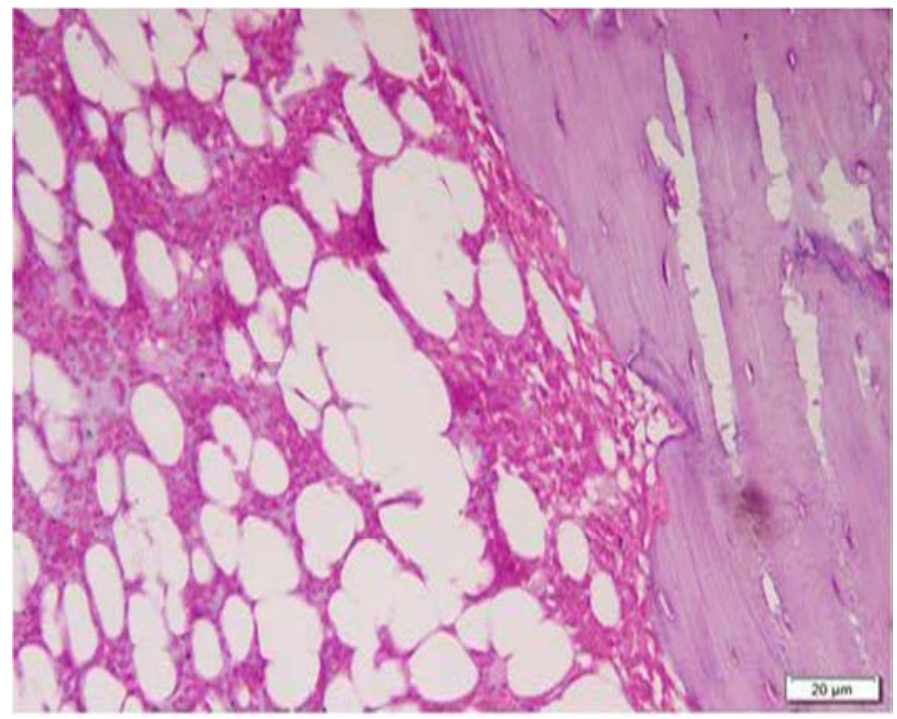

Figure 12. A photomicrograph of a longitudinal section of rat femur compact bone from group III (OVARIECTOMY)showing irregularly eroded endosteal surface . Resorption cavities are also observed. $(H \& E \times 200)$. 


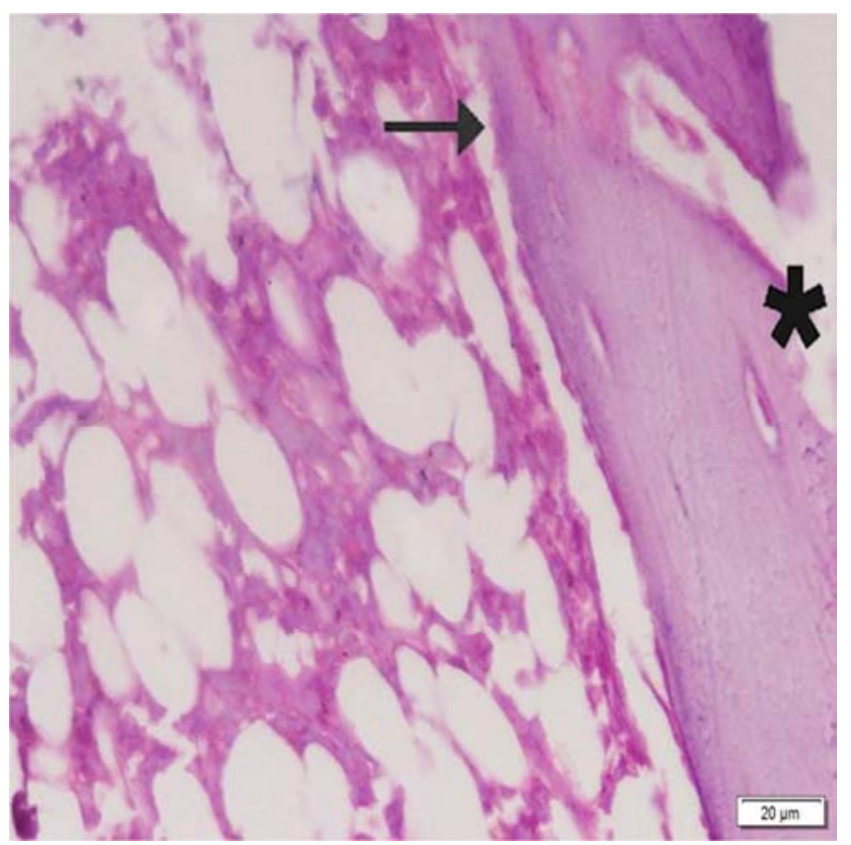

Figure 13. A photomicrograph of a longitudinal section of rat femur compact bone from group IV (OVARIECTOMY +DEX) showing showing thinned out trabeculae with deep erosion (star). There is apparent increase in the bone marrow adipocytes compared with control rats with quiescent osteoblast (arrow). $(H \& E \times 400)$.

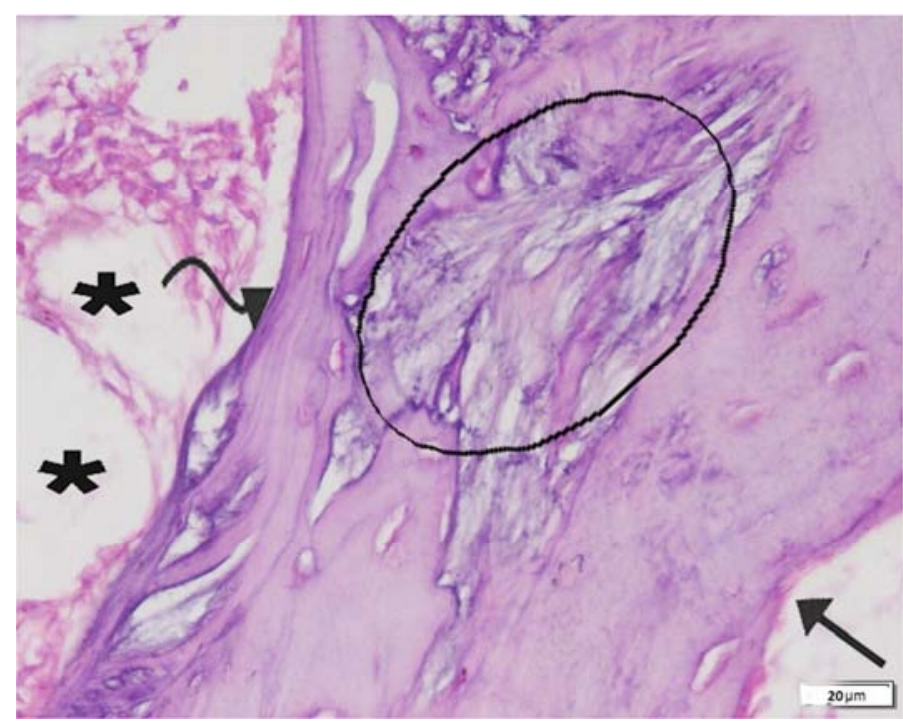

Figure 14. A photomicrograph of a longitudinal section of rat femur compact bone from group IV (OVARIECTOMY +DEX) showing irregularly eroded both periosteal (arrow) and endosteal surfaces (curved arrow). Large resorption cavities with faintly stained matrix in bone trabeculae are observed (circle). Huge adipocytes seen in the bone marrow cavity (stars). $(H \& E \times 400)$.

\section{Discussion}

The current study confirms and extends the findings of an inverse association between bone strength indices and

insulin resistance, noted by [13]. These findings are also consistent with those from studies in adolescents[14], young adults [15] bone marrow transplant patients [16], and diabetics [17] that have found associations between greater insulin resistance and reduced bone mass. Physiologically low estradiol has an effect on the skeleton in elderly women possibly by reducing skeletal remodeling [18]. The presence of osteoporosis related to diabetes mellitus is less acknowledged.In patients with type 2 diabetes mellitus the risk of osteopenia is not clear [19]. There is evidence that a decreased bone formation is one major mechanism leading to reduced bone mass in diabetics. The association between diabetes mellitus and osteoporosis remains controversial [20].

This study demonstrated that a longitudinal section of rat femur compact bone from group IV (OVARIECTOMY + DEX) showed thinned out trabeculae with deep erosions

In sham DEX group and Ovariectomy group the histological changes in the bone shoed only either eroded endostium or periosteum with no signs of subperiosteal new bone deposition

In this study, Ovariectomy DEX group has highly significant increase in relative cortical resorption compared to ovaiectomy and sham DEX groups, also ovariectomy and DEX group has highly significant decrease in bone thickness compared to ovariectomy and sham DEX groups. Our findings are in contradistinction to several previous studies that have documented higher bone mineral density in T2DM [21-22] despite the increased risk of fractures in T2DM [2328]. A deleterious role for insulin resistance on bone is also consistent with experiments in mouse models that suggest that osteoblasts are insulin target cells [29] .Mice deficient in osteoblast-specific insulin receptors have reduced expression of genes implicated in bone resorption (CathepsinK and Tcirg1), less acidification of bone extracellular matrix, significantly smaller resorption pits and markedly lower serum levels of bone resorption marker, CTx

Further, it was recently noted that in Wistar rats with an obese, insulin resistant condition induced by a 12 week high fat diet, there was significant impairment of osteoblastic insulin signaling and osteoblast proliferation, with increased osteoblastic apoptosis culminating in osteoporosis in the jaw bone, compared to baseline, measured using micro computerized tomography (CT) of mandibular bone. Previous studies have also noted the lower spine bone volume in T2DM subjects. A recent study found that bone cross-sectional area is also lower in T2DM, suggesting a deficit in periosteal apposition which is normally stimulated by skeletal loading. Taken together, these studies suggest that increased insulin resistance and/or hyperinsulinemia, may interfere with the usual anabolic response in bone to skeletal loading, so that bone strength relative to load is negatively affected. Our study confirms and extends the findings of an inverse association between bone strength indices and insulin resistance, noted by Ishii et al [31]

\section{Conclusions}

Hyperinsulinemia and insulin resistance induced by long term glucocorticoids therapy affects negatively bone mass either alone or combined with ovariectomy .Induced 
menopause with loss of the anabolic hormone oestrogen have more effect in decreasing bone mass, which may lead to increased bone fractures in menopausal women taking glucocorticoids therapy for long times. This needs further research to uncover the biological mechanisms by which insulin resistance induce by glucocorticoids could deleteriously affect bone health.

\section{Acknowledgements}

I would like to thank Professor Mohamed Shaaban (Professor of Histology, Prince Sattam Ibn Abdulaziz University) for his continuous support and encouragement throughout this research, this work wouldn't be completed without his valuable scientific guidance.

\section{References}

[1] Davis GF: Adverse effects of corticosteroids: II. Systemic. Clin Dermatol 1986, 4[1]:161-169.

[2] Besse C, Nicod N, Tappy L: Changes in insulin secretion and glucose metabolism induced by dexamethasone in lean and obese females.Obes Res 2005, 13:306-311.

[3] Strotmeyer ES, Cauley JA, Schwartz AV, Nevitt MC, Resnick HE, Bauer DC, Tylavsky FA, de Rekeneire N, Harris TB, Newman AB. Nontraumatic fracture risk with diabetes mellitus and impaired fasting glucose in older white and black adults: the health, aging, and body composition study. Arch Intern Med. 2005;165(14):1612-1617. [Pub Med]

[4] Vestergaard P. Discrepancies in bone mineral density and fracture risk in patients with type 1 and type 2 diabetes--a meta-analysis. Osteoporos Int. 2007;18(4):427-444. [Pub Med]

[5] de Paula FJ, Horowitz MC, Rosen CJ. Novel insights into the relationship between diabetes and osteoporosis. Diabetes Metab Res Rev. 2010;26(8):622-630. [PMC free article] [Pub Med]

[6] Yaturu S. Diabetes and skeletal health. J Diabetes. 2009;1(4):246-254. [Pub Med]

[7] Brauer CA, Coca-Perraillon M, Cutler DM, Rosen AB. Incidence and mortality of hip fractures in the United States. Jama. 2009;302(14):1573-1579. [PMC free article] [Pub Med]

[8] RaiszLG.(2005)Pathogenesisofosteoporosis:concepts,conflicts ,andprospects $>$ JClinInvest 115:3318-

3325.doi:10.1172/JCI27071 [PMC free article]\{Pub Med]

[9] Chen X,Wang Z,Duan N,Zhu G,

[10] Schwartz EM,Xie C.(2017) Osteoblast-osteoclast interactions.Connective Tissue Res. 8:1-9[PMC free article][Pub Med]

[11] Ishii S, Cauley JA, Crandall CJ, Srikanthan P, Greendale GA, Huang MH, Danielson ME, Karlamangla AS. Diabetes and femoral neck strength: findings from the Hip Strength Across the Menopausal Transition Study. J Clin Endocrinol Metab. 2012;97(1):190-197. [PMC free article] [Pub Med]
[12] do Prado WL, de Piano A, Lazaretti-Castro M, de Mello MT, Stella SG, Tufik S, do Nascimento CM, Oyama LM, Lofrano MC, Tock L, Caranti DA, Damaso AR. Relationship between bone mineral

[13] density, leptin and insulin concentration in Brazilian obese adolescents. J Bone Miner Metab. 2009;27(5):613619.[Pub Med]Lucey AJ, Paschos GK, Thorsdottir I, Martinez JA, Cashman KD, Kiely M. Young overweight and obese women with lower circulating osteocalcin concentrations exhibit higher insulin resistance and concentrations of C-reactive protein. Nutr Res. 2013;33(1):67-75. [Pub Med]

[14] Faulhaber GA, Premaor MO, Moser Filho HL, Silla LM, Furlanetto TW. Low bone mineral density is associated with insulin resistance in bone marrow transplant subjects. Bone Marrow Transplant. 2009;43(12):953-957. [Pub Med]

[15] Arikan S, Tuzcu A, Bahceci M, Ozmen S, Gokalp D. Insulin resistance in type 2 diabetes mellitus may be related to bone mineral density. J Clin Densitom. 2012;15(2):186-190. [Pub Med].

[16] Bruce Ettingers,Alice Pressman,Peter Sklarin,Douglas C.Bauer,Jane A.Cauley,Steven R.Cumming, The journal of Clinical endocrinology and Metabolism, volume 83,Issue 7,1 July 1998,page 2239-2243.

[17] Leidig-Bruckner G,Ziegler r:Diabetes mellitus a risk for osteoporosis?,Exp Clin Endocrinol,Diabetes,2001;109 Supp12:S493-514.

[18] Bouillon R.Diabetic bone disease,Calcif Tissue Int 1991;49-155.

[19] Haffner SM, Bauer RL. The association of obesity and glucose and insulin concentrations with bone density in premenopausal and postmenopausal women. Metabolism. 1993;42(6):735-738. [Pub Med]

[20] Meema HE, Meema S. The relationship of diabetes mellitus and body weight to osteoporosis in elderly females. Can Med Assoc J. 1967;96(3):132-139. [PMC free article] [Pub Med]

[21] Bonds DE, Larson JC, Schwartz AV, Strotmeyer ES, Robbins J, Rodriguez BL, Johnson KC, Margolis KL. Risk of fracture in women with type 2 diabetes: the Women's Health Initiative Observational Study. J Clin Endocrinol Metab. 2006;91(9):3404-3410. [Pub Med]

[22] de L, II, van der Klift M, de Laet CE, van Daele PL, Hofman A, Pols HA. Bone mineral density and fracture risk in type-2 diabetes mellitus: the Rotterdam Study. Osteoporos Int. 2005;16(12):1713-1720.[Pub Med]

[23] Schwartz AV, Vittinghoff E, Bauer DC, Hillier TA, Strotmeyer ES, Ensrud KE, Donaldson MG, Cauley JA, Harris TB, Koster A, Womack CR, Palermo L, Black DM. Association of BMD and FRAX score with risk of fracture in older adults with type 2 diabetes. Jama. 2011;305(21):2184-2192. [PMC free article][Pub Med]

[24] Dobnig H, Piswanger-Solkner JC, Roth M, ObermayerPietsch B, Tiran A, Strele A, Maier E, Maritschnegg P, Sieberer C, Fahrleitner-Pammer A. Type 2 diabetes mellitus in nursing home patients: effects on bone turnover, bone mass, and fracture risk. J Clin Endocrinol Metab. 2006;91(9):33553363.[Pub Med] 
[25] Rivadeneira F, Zillikens MC, De Laet CE, Hofman A, Uitterlinden AG, Beck TJ, Pols HA. Femoral neck BMD is a strong predictor of hip fracture susceptibility in elderly men and women because it detects cortical bone instability: the Rotterdam Study. J Bone Miner Res. 2007;22(11):1781-1790. [Pub Med]

[26] Strotmeyer ES, Cauley JA, Schwartz AV, Nevitt MC, Resnick HE, Bauer DC, Tylavsky FA, de Rekeneire N, Harris TB, Newman AB. Nontraumatic fracture risk with diabetes mellitus and impaired fasting glucose in older white and black adults: the health, aging, and body composition study. Archives of internal medicine. 2005;165(14):1612-1617. [Pub Med]

[27] Fulzele K, Riddle RC, DiGirolamo DJ, Cao X, Wan C, Chen D, Faugere MC, Aja S, Hussain MA, Bruning JC, Clemens TL. Insulin receptor signaling in osteoblasts regulates postnatal bone acquisition and body composition. Cell. 2010;142(2):309-319. [PMC free article] [Pub Med]

[28] Ferron M, Wei J, Yoshizawa T, Del Fattore A, DePinho RA, Teti A, Ducy P, Karsenty G. Insulin signaling in osteoblasts integrates bone remodeling and energy metabolism. Cell. 2010;142(2):296-308.[PMC free article] [Pub Med]
[29] Pramojanee SN, Phimphilai M, Kumphune S, Chattipakorn N, Chattipakorn SC. Decreased jaw bone density and osteoblastic insulin signaling in a model of obesity. $J$ Dent Res. 2013;92(6):560-565.[Pub Med]

[30] Strotmeyer ES, Cauley JA, Schwartz AV, Nevitt MC, Resnick HE, Zmuda JM, Bauer DC, Tylavsky FA, de Rekeneire N, Harris TB, Newman AB. Diabetes is associated independently of body composition with BMD and bone volume in older white and black men and women: The Health, Aging, and Body Composition Study. J Bone Miner Res. 2004;19(7):1084-1091. [Pub Med]

[31] Petit MA, Paudel ML, Taylor BC, Hughes JM, Strotmeyer ES, Schwartz AV, Cauley JA, Zmuda JM, Hoffman AR, Ensrud $\mathrm{KE}$. Bone mass and strength in older men with type 2 diabetes: the Osteoporotic Fractures in Men Study. J Bone Miner Res. 2010;25(2):285-291. [PMC free article] [Pub Med]

[32] Ishii S, Cauley JA, Crandall CJ, Srikanthan P, Greendale GA, Huang MH, Danielson ME, Karlamangla AS Diabetes and femoral neck strength: findings from the Hip Strength Across the Menopausal Transition Study. J Clin Endocrinol Metab. 2012 Jan; 97(1):190-7. 